\title{
Rational Design of a Low-Cost, High-Performance Metal-Organic Framework for Hydrogen Storage and Carbon Capture
}

\author{
Matthew Witman, ${ }^{\dagger, \#}$ Sanliang Ling, ${ }^{\ddagger}, \# \odot$ Andrzej Gladysiak, ${ }^{\S}$ Kyriakos C. Stylianou, ${ }^{\S}{ }^{\circledR}$ Berend Smit, ${ }^{\dagger} \S_{\odot}$ \\ Ben Slater, ${ }^{\ddagger}$ and Maciej Haranczyk ${ }^{*}, \|, \perp$ \\ ${ }^{\dagger}$ Department of Chemical and Biomolecular Engineering, University of California, Berkeley 94720, California, United States \\ ${ }^{\ddagger}$ Department of Chemistry, University College London, 20 Gordon Street, London WC1H 0AJ, U.K. \\ ${ }^{\S}$ Laboratory of Molecular Simulation, Institut des Sciences et Ingénierie Chimiques, Valais, Ecole Polytechnique Fédérale de Lausanne \\ (EPFL), Rue de l' Industrie 17, CH-1951 Sion, Switzerland \\ "Computational Research Division, Lawrence Berkeley National Laboratory, Berkeley, California 94720, United States \\ ${ }^{\perp}$ IMDEA Materials Institute, C/Eric Kandel 2, 28906 Getafe, Madrid, Spain
}

\section{Supporting Information}

\begin{abstract}
We present the in silico design of a MOF-74 analogue, hereon known as $\mathrm{M}_{2}$ (DHFUMA) $[\mathrm{M}=\mathrm{Mg}, \mathrm{Fe}, \mathrm{Co}$, $\mathrm{Ni}, \mathrm{Zn}$ ], with enhanced small-molecule adsorption properties over the original $\mathrm{M}_{2}$ (DOBDC) series. Constructed from 2,3dihydroxyfumarate (DHFUMA), an aliphatic ligand which is smaller than the aromatic 2,5-dioxidobenzene-1,4-dicarboxylate (DOBDC), the $\mathrm{M}_{2}$ (DHFUMA) framework has a reduced channel diameter, resulting in higher volumetric density of open metal sites and significantly improved volumetric hydrogen $\left(\mathrm{H}_{2}\right)$ storage potential. Furthermore, the reduced distance between two adjacent open metal sites in

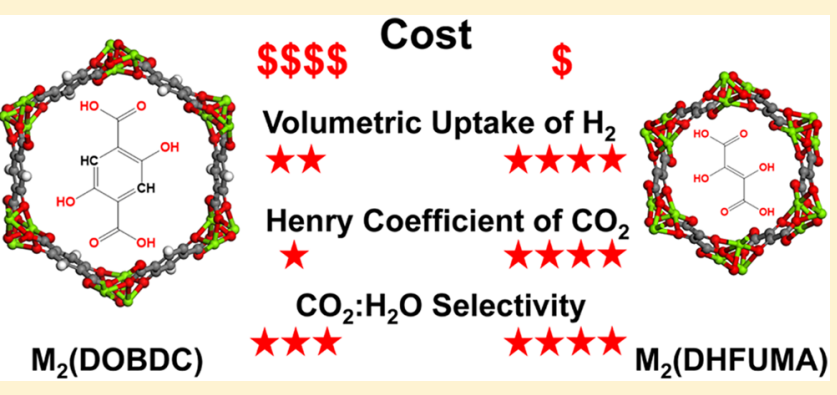
the pore channel leads to a $\mathrm{CO}_{2}$ binding mode of one molecule per two adjacent metals with markedly stronger binding energetics. Through dispersion-corrected density functional theory (DFT) calculations of guest-framework interactions and classical simulation of the adsorption behavior of binary $\mathrm{CO}_{2}: \mathrm{H}_{2} \mathrm{O}$ mixtures, we theoretically predict the $\mathrm{M}_{2}(\mathrm{DHFUMA})$ series as an improved alternative for carbon capture over the $\mathrm{M}_{2}$ (DOBDC) series when adsorbing from wet flue gas streams. The improved $\mathrm{CO}_{2}$ uptake and humidity tolerance in our simulations is tunable based upon metal selection and adsorption temperature which, combined with the significantly reduced ligand expense, elevates this material's potential for $\mathrm{CO}_{2}$ capture and $\mathrm{H}_{2}$ storage. The dynamical and elastic stabilities of $\mathrm{Mg}_{2}$ (DHFUMA) were verified by hybrid DFT calculations, demonstrating its significant potential for experimental synthesis.
\end{abstract}

\section{INTRODUCTION}

Porous materials have been extensively studied as potential adsorbents in energy and environmental applications including hydrogen storage and carbon capture. ${ }^{1-7}$ Among the various porous solids, metal-organic frameworks (MOFs), which are typically constructed from building blocks including inorganic metal (oxide) secondary building units (SBUs) and organic ligands, have attracted significant interest since their composition (i.e., chemical functionality) and structure (e.g., pore topology and sizes and internal surface areas) are highly tunable. ${ }^{8}$ Hence their performance for a given application can be systematically improved by rational materials design. ${ }^{9-14}$ With respect to hydrogen storage and carbon capture (e.g., from flue gas) applications, one of the most important factors which dictates the amount of $\mathrm{H}_{2}$ and $\mathrm{CO}_{2}$ that can be adsorbed in a MOF material is the adsorbate-adsorbent interactions, with MOF-74 being considered as one of the best performing MOFs because of the presence of a high density of open metal sites that interact strongly with $\mathrm{H}_{2}$ and $\mathrm{CO}_{2}$ molecules. ${ }^{15-17}$
Despite the many advantages of MOFs that result from high tunability of chemistry and structure, the cost of MOF production is still a major factor that impedes their largescale industrial applications. Apart from the capital investment in infrastructures, the cost of MOF production consists largely of raw materials (including metal salts and organic ligands) and processing, which include but are not limited to nonreusable organic solvents and cost associated with activation. For MOF74 with a molecular formula $\mathrm{M}_{2}$ (DOBDC) $(\mathrm{M}=\mathrm{Mg}, \mathrm{Zn}, \mathrm{Fe}$, etc. and $\mathrm{DOBDC}=2,5$-dioxido-1,4-benzenedicarboxylate), the major cost of raw materials comes from the organic ligand (i.e., DOBDC). Taking Mg-MOF-74 as an example, the cost of metal salts, usually $\mathrm{MgCl}_{2}$, can almost be neglected; i.e., it accounts for only a small percentage of the expense of organic ligands. Indeed, MOFs built from much cheaper organic ligands

Received: October 13, 2016

Revised: December 16, 2016

Published: December 16, 2016 
will need to be developed before they can be widely used in industry in large quantities. Generally speaking, larger and longer aromatic organic ligands are more expensive than smaller and shorter aliphatic ligands. However, the majority of the MOFs synthesized so far features aromatic organic ligands because the coordination-driven self-assembly of building blocks to produce porous crystalline MOFs requires the molecular precursor to be rigid and possess proper directionality. ${ }^{18}$ Such properties are more likely to appear in conjugated organic ligands, e.g., $\mathrm{DOBDC}$ and $\mathrm{BDC}(\mathrm{BDC}=1,4-$ benzenedicarboxylate), both of which are frequently used in the synthesis of MOFs. On the other hand, most of the aliphatic ligands are flexible and do not have sites to form directional metal-ligand bonds, and they are less likely to form porous and crystalline solids with metal centers. Therefore, aliphatic ligands are rarely employed in MOF synthesis. Nevertheless, there are still several MOFs based on aliphatic ligands, ${ }^{19-21}$ including the commercially available aluminum fumarate (Basolite A520). ${ }^{22}$ However, there are no open metal sites in these MOFs, thereby limiting their $\mathrm{CO}_{2}$ and $\mathrm{H}_{2}$ storage potential at low and ambient pressures. It would be extremely useful to develop a MOF-74 analogue featuring both open metal sites, which lead to enhanced adsorbate-adsorbent interactions and higher gas uptake at ambient pressure, and cheap aliphatic linkers, which lower the overall raw materials cost. To the best of our knowledge, all the MOF-74 analogues which have been experimentally synthesized so far were constructed from longer, aromatic organic linkers and are therefore likely to be more expensive with limited improvement on gas adsorption capacity in low to ambient pressure regimes.

Another popular approach to increase the gas adsorption capacity of MOFs is to synthesize MOFs with expanded pores and larger internal surface areas, e.g., by replacing the DOBDC linker in MOF-74 with longer linkers. ${ }^{23}$ We investigated the effectiveness of pore expansion in MOF-74 analogues in one of our recent high-throughput screening studies, ${ }^{24}$ whereby we developed a novel in silico crystal assembly algorithm that differed from previous approaches ${ }^{25-29}$ to create a library of MOF-74 analogues which exhibit 1-D metal-oxide rod building units. ${ }^{30}$ We found that the gravimetric uptake of $\mathrm{CO}_{2}$ dropped significantly in MOF-74 analogues with higher pore volumes due to the spatial and gravimetric dilution of the open metal sites which serve as the strong adsorption sites for $\mathrm{CO}_{2}$ molecules. Thus, the increased pore volume in these analogues (which results from construction with extended ligands) sacrifices gravimetric uptake and further complicates synthesis by introducing more complex organic molecule building units and by potentially reducing mechanical stability. Therefore, larger pore sizes are not always desirable. While many efforts have been made to tune and improve upon the exceptional small molecule adsorption properties of the original MOF-74 framework,,$^{31-35}$ we undertake a rational design approach to further improve the gas adsorption capabilities in MOF-74 analogues by increasing the density of open metal sites, e.g., by replacing the DOBDC linker with a smaller molecule. While DOBDC represents the smallest aromatic molecule that satisfies the topological requirement of MOF-74, an even smaller molecule can be identified from the thousands of aliphatic molecules which are smaller in size than DOBDC.

In this work, we rationally design in silico a MOF-74 analogue based on a cheaper and commercially available aliphatic ligand, i.e., DHFUMA (DHFUMA = 2,3-dihydroxyfumarate), and simulate its $\mathrm{H}_{2}, \mathrm{CO}_{2}$, and $\mathrm{H}_{2} \mathrm{O}$ adsorption properties, based on extensive previous work dedicated to describing the energetic interactions of small molecules in the MOF-74 framework. ${ }^{36-40}$ Namely, we predict significantly improved $\mathrm{H}_{2}$ volumetric storage capacity, increased low-pressure $\mathrm{CO}_{2}$ adsorption, and higher $\mathrm{CO}_{2}: \mathrm{H}_{2} \mathrm{O}$ selectivity in the $\mathrm{M}_{2}$ (DHFUMA) series than the $\mathrm{M}_{2}$ (DOBDC) series. The cost (per mol) of DHFUMA is lower than that of DOBDC by more than $80 \%$ from the commercial vendor Sigma-Aldrich, and the volumetric density of open metal sites in $\mathrm{M}_{2}$ (DHFUMA) is twice of that of $\mathrm{M}_{2}$ (DOBDC). Typical protocols used to synthesize $\mathrm{M}_{2}$ (DOBDC) have been tested and shown to result in a crystalline material that is not the desired $\mathrm{M}_{2}$ (DHFUMA) product (see Supporting Information); however, calculation of the elastic constants and vibrational frequencies demonstrates the dynamical and mechanical stability of $\mathrm{M}_{2}$ (DHFUMA) and provides justification that the material can be synthesized. $\mathrm{M}_{2}$ (DHFUMA), if it can be synthesized in large quantities, has the potential to be a better candidate than $\mathrm{M}_{2}$ (DOBDC) for industrial applications including hydrogen storage and carbon capture.

\section{METHODS}

In Silico Crystal Design. Part of our recent work has focused on the in silico crystal design of 1-D rod MOFs. ${ }^{24}$ The building blocks of these MOFs are embedded in threedimensional space by an optimization routine that is constrained by geometric rules that must hold for a 1-D rod MOF. Utilizing this method allows for facile substitution of DOBDC for DHFUMA into the MOF-74 framework and quickly creates an accurate starting crystal structure for DFT optimization. Figure 1 demonstrates the analogous connectivity groups in DHFUMA and DOBDC. We believe this to be the smallest possible ligand with which a MOF-74 analogue can be constructed. Dispersion-corrected DFT optimization was performed to relax the $\mathrm{M}_{2}$ (DOBDC) and $\mathrm{M}_{2}$ (DHFUMA) frameworks and obtain partial atomic charges for each unique atom type in the framework.

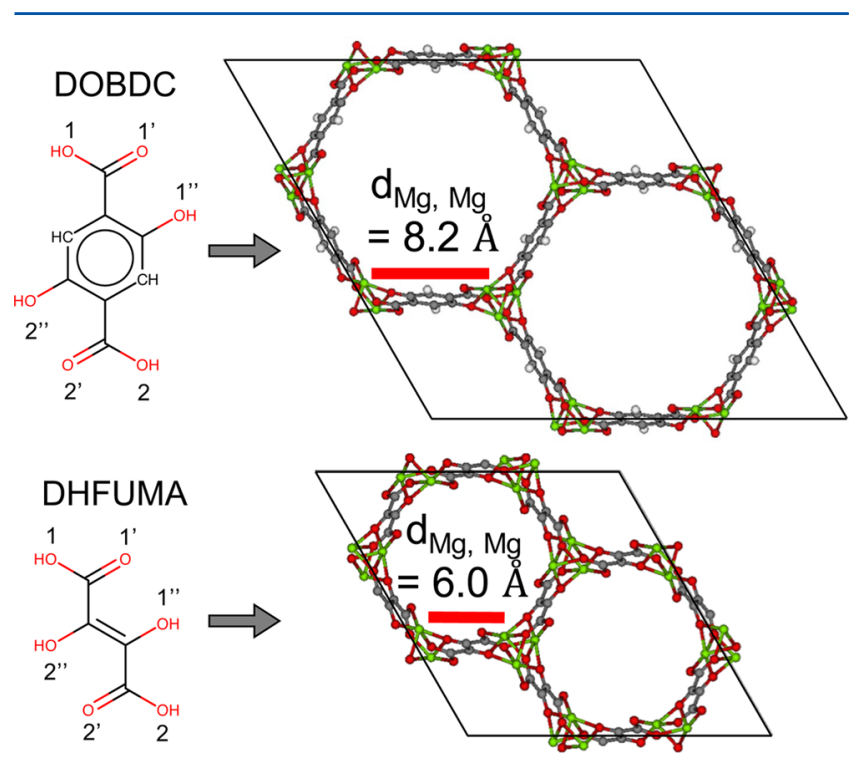

Figure 1. DOBDC ligand and framework is visually compared to the DHFUMA ligand and framework. $\left(1,1^{\prime}, 1^{\prime \prime}\right)$ oxygens connect to one metal rod in the MOF-74-type framework, and $\left(2,2^{\prime}, 2^{\prime \prime}\right)$ connect to an adjacent metal rod. The distance between adjacent open metal sites is shown to be $2 \AA$ shorter in the $\mathrm{Mg}_{2}$ (DHFUMA) framework. 
DFT Calculations. A majority of the periodic density functional theory calculations, including geometry and cell optimizations, have been performed using the CP2K code which uses a mixed Gaussian/plane-wave basis set. ${ }^{41,42}$ We have used both gradient-corrected (i.e., $\mathrm{PBE}^{43}$ ) and hybrid density functional (i.e., PBE0 ${ }^{44,45}$ with $25 \%$ Hartree-Fock exchange) methods. It is known that a correct description of the dispersion interactions is important to predict the MOF structures and host-guest interactions in MOFs. ${ }^{46,47}$ In this work, we have used one of the most popular pairwise additive descriptions of the dispersion interactions as developed by Grimme et al., i.e., the D 3 method $^{48}$ with the Axilrod-TellerMuto three-body terms, in combination with the conventional PBE and PBE0 functionals. The same method was used in our previous work on MIL-53, ${ }^{49,50} \mathrm{UiO}-66,{ }^{51}$ and MOF- $74^{24}$ types of MOFs, and we achieved very good agreement between theory and experimental results on structures and calorimetric measurements. We note that a hybrid functional is necessary here to provide a correct description of the electronic structures and host-guest interactions of MOF-74 materials featuring $\mathrm{M}^{2+}$ cations with unpaired electrons, including $\mathrm{Mn}^{2+}, \mathrm{Fe}^{2+}, \mathrm{Co}^{2+}$, $\mathrm{Ni}^{2+}$, and $\mathrm{Cu}^{2+}$. The Hartree-Fock exchange calculations, which are part of the hybrid DFT functional PBE0, were performed and significantly accelerated using the auxiliary density matrix method (ADMM), ${ }^{52}$ which enables us to consider relatively large systems (with the largest system containing 489 atoms) at the hybrid DFT level. The partial atomic charge analysis was performed using the REPEAT method proposed by Campana et al., ${ }^{53}$ which was recently implemented into the $\mathrm{CP} 2 \mathrm{~K}$ code based on a restrained electrostatic potential framework. ${ }^{54}$ The REPEAT method calculates partial atomic charges from electrostatic potentials determined from DFT calculations, and only the grid points outside the van der Waals radii of each atom were included in the fitting. We have used partial atomic charges determined using the REPEAT scheme in our recent work on MOF-74, in which very good agreement was obtained between theory and experiment on the adsorption isotherms of $\mathrm{CO}_{2}$ molecules. ${ }^{24}$ The vibrational frequency and elastic constant calculations were performed using the CRYSTAL code ${ }^{55,56}$ with the B3LYP hybrid functional. ${ }^{57}$ More details of the calculations are included in the Supporting Information.

Classical Simulations and Pore Characterization. A critical component in the classical molecular simulation of nanoporous materials is the parametrization of classical potential energy functions (or force fields) that can accurately describe the energetics of host-guest systems. Many times offthe-shelf force fields such as $\mathrm{UFF}^{58}$ or Dreiding ${ }^{59}$ are used in lieu of a more accurate alternative, but this approach breaks down with MOFs that contain complex electronic structure features such as open metal sites. ${ }^{37}$ Several different approaches have been used specifically to generate force fields which successfully describe gas interactions in MOF-74 type frameworks which contain these open metal sites. ${ }^{37,60,61}$ Pham et al. used a many-body polarization approach to classically capture the complex $\mathrm{H}_{2}$-open metal site interactions in the $\mathrm{Mg}_{2}$ (DOBDC) framework and later extended their force field development to the entire metal series. ${ }^{40,62}$ In this work, the model of Pham was used to model $\mathrm{H}_{2}$ adsorption in $\mathrm{Mg}_{2}$ (DOBDC) and $\mathrm{Mg}_{2}$ (DHFUMA), and we refer the reader to these publications for further details. The grand canonical Monte Carlo (GCMC) simulations of $\mathrm{H}_{2}$ with many-body polarization were calculated with the RASPA2 software package. $^{63}$

Mercado et al. used a recently developed approach to parametrize the potential energy surface for the isoreticular series $\mathrm{M}_{2}(\mathrm{DOBDC})[\mathrm{M}=\mathrm{Mg}, \mathrm{Mn}, \mathrm{Fe}, \mathrm{Co}, \mathrm{Ni}, \mathrm{Zn}]$ such that classical molecular simulation of $\mathrm{CO}_{2}$ and $\mathrm{H}_{2} \mathrm{O}$ could be performed for the entire metal series for the first time. ${ }^{39}$ The parametrization was peformed by calculating DFT single-point energies along the path of minimum repulsion between unique guest-host pairwise types to accurately capture the repulsive behavior between the guest and the excess electon density at the open metal sites. We adopt this force field parametrization for studying the adsorption properties of $\mathrm{CO}_{2}$ and $\mathrm{H}_{2} \mathrm{O}$ in DHFUMA and refer the reader to this publication for specific details and the parameters themselves. The unique types assigned to each atom in the DHFUMA crystal structure and their correspondence to the atom types of Mercado's force field are shown in the Supporting Information, in addition to a justification for the transferability of the force field. GCMC simulations were executed to calculate adsorption isotherms and isosteric heats of adsorption of the frameworks under consideration. An annealing minimization scheme was used to determine the classical binding energy of adsorbates in all analogues. In this scheme, an NVT ensemble Monte Carlo simulation consisting of one asorbate molecule is successively quenched from $T=298 \mathrm{~K}$ to $T=1 \mathrm{~K}$. The potential energy of the final configuration in the $T=1 \mathrm{~K}$ simulation then corresponds to the classical binding energy. The porosity characterization of all frameworks was performed with the Zeo ++ application using the high accuracy settings. ${ }^{64,65}$

\section{RESULTS}

Porosity Characterization. The channel geometry of the $\mathrm{Mg}$ analogues of the DHFUMA and DOBDC series were analyzed by $\mathrm{Zeo}++$ to demonstrate the differences in porosity which are later shown to have a significant impact on the adsorption properties of the two frameworks. A probe radius of $1.65 \AA$ was used which corresponds to the kinetic diamter of $\mathrm{CO}_{2}$. Table 1 summarizes these important geometric quantities.

Table 1. Accessible Surface Area (ASA), Accessible Volume (AV), Largest Included Sphere $\left(D_{\mathrm{I}}\right)$, Largest Free Sphere $\left(D_{\mathrm{F}}\right)$, Open Metal Site Volumetric Density $\left(\rho_{\mathrm{Mg}}\right)$, and Open Metal Site Weight Percent of Two Frameworks: $\mathrm{Mg}_{2}$ (DHFUMA) vs $\mathrm{Mg}_{2}$ (DOBDC)

\begin{tabular}{|c|c|c|c|c|c|c|}
\hline & ASA & AV & $D_{\text {I }}$ & $D_{\mathrm{F}}$ & $\rho_{\mathrm{Mg}}$ & wt $\% \mathrm{Mg}$ \\
\hline ligand & {$\left[\mathrm{m}^{2} / \mathrm{g}\right]$} & {$\left[\mathrm{cm}^{3} / \mathrm{g}\right]$} & $[\AA]]$ & {$[\AA]$} & {$\left[\mathrm{Mg} / \AA^{3}\right]$} & [\%] \\
\hline DOBDC & 1782 & 0.350 & 11.8 & 11.1 & 0.0044 & 20.0 \\
\hline DHFUMA & 1043 & 0.095 & 7.6 & 6.3 & 0.0084 & 25.2 \\
\hline
\end{tabular}

We note that the distance between the centers of two metal rods opposite each other in a single hexagon of DHFUMA, i.e., the approximate diameter of a single channel, is equal to $12.6 \AA$. When accounting for the Van der Waal's radii of the framework atoms in DHFUMA, the largest free and included spheres are close to half of this diameter as shown in Table 1. Interestingly, the typical diameter of single-wall carbon nanotubes (SWNTs), depending on the chirality indices, can range from $6.2(n+m=$ 8) to $12.2(n+m=18)$ for the lowest energy tube for each combination of chirality indices. ${ }^{66}$ We have therefore designed a MOF with a channel geometry that is essentially comparable to a SWNT but with a significantly higher degree of chemical 
diversity due to the presence of oxygens and open metal sites decorating the inside of the channel. The proximity and increased volumetric density of open metal sites in the DHFUMA structure compared to the DOBDC structure will later be shown to result in a new $\mathrm{CO}_{2}$ binding configuration. The volumetric densities of open metal sites in $\mathrm{Mg}_{2}$ (DHFUMA) and $\mathrm{Mg}_{2}(\mathrm{DOBDC})$ are $0.0084 \mathrm{Mg} / \AA^{3}$ and $0.0044 \mathrm{Mg} / \AA^{3}$, respectively. One in every six atoms in DHFUMA is an open metal site, whereas one in every nine atoms in DOBDC is an open metal site. With nearly two times the volumetric metal site density and one and a half times the molar metal site density of DOBDC (in addition to the reduced interatomic distance between adjacent $\mathrm{Mg}$ atoms in each channel), DHFUMA contains a spatial configuration of open metal sites that is more favorable for hydorgen storage and $\mathrm{CO}_{2}$ capture. Additional pertinent crystallographic data for $\mathrm{Mg}_{2}$ (DOBDC) and $\mathrm{Mg}_{2}$ (DHFUMA) are included in the Supporting Information.

Predictions on Material Stability. To verify whether $\mathrm{M}_{2}$ (DHFUMA) is stable and therefore has the potential to be synthesized experimentally, we calculated the vibrational frequencies and elastic constants. Our calculated vibrational frequencies and the full elastic matrix of $\mathrm{Mg}_{2}$ (DHFUMA) are shown in the Supporting Information. We find all the vibrational modes of $\mathrm{Mg}_{2}$ (DHFUMA) have positive frequencies, demonstrating its dynamical stability. We further verify the elastic stability of $\mathrm{Mg}_{2}$ (DHFUMA) against the Born stability criteria, ${ }^{67}$ and we find the calculated elastic constants of $\mathrm{Mg}_{2}$ (DHFUMA) satisfy all the necessary and sufficient stability conditions (see the Supporting Information), ${ }^{68}$ demonstrating $\mathrm{Mg}_{2}$ (DHFUMA) to be mechanically stable. We expect $\mathrm{M}_{2}$ (DHFUMA) based on other metals to have the same behavior and suggest these materials have the potential to be synthesized in future experiments. The results of the mechanical and dynamical stability calculations are not surprising, especially since the metal oxide rod $\mathrm{M}-\mathrm{O}$ coordination environment is identical to $\mathrm{M}_{2}$ (DOBDC) and since DHFUMA is an experimentally validated ligand with a fully conjugated backbone exhibiting a planar geometry between the two connection groups (see Figure 1). The synthetic difficulties arise in finding the necessary reaction conditions to yield the correct crystalline $\mathrm{M}_{2}$ (DHFUMA) product, the details of which are elaborated in the Supporting Information.

Enhanced $\mathrm{H}_{2}$ Storage Potential. The doubling of the volumetric density of open metal sites results in a factor of 2 increase in the simulated volumetric $\mathrm{H}_{2}$ storage capacity of $\mathrm{Mg}_{2}$ (DHFUMA) over $\mathrm{Mg}_{2}(\mathrm{DOBDC})$ at cryogenic temperatures. Utilizing the many-body polarization scheme implemented in the RASPA2 package and the polarizable model of Pham et al. ${ }^{40}$ to compute $\mathrm{H}_{2}$ potential energy interactions in $\mathrm{Mg}_{2}$ (DOBDC), we simulate the adsorption isotherms of both $\mathrm{Mg}_{2}$ (DOBDC) and $\mathrm{Mg}_{2}$ (DHFUMA) at $77 \mathrm{~K}$. We assumed that the force field is transferable and adopt all model parameters of Pham with the exception of the frameworks' partial atomic charges for which we use the values derived from our REPEAT analysis which are summarized in the Supporting Information. Figure 2(a) demonstrates a good agreement of our isotherm with the theoretical isotherm of Pham et al. and the experimental isotherm of Dietzel et al. (data extracted from ref 40 and ref 69, respectively) for $\mathrm{Mg}_{2}$ (DOBDC) at $77 \mathrm{~K}$. Our simulated isotherm as generated by RASPA2 slightly overpredicts the gravimetric uptake (by $\sim 20 \%$ at 1 bar) shown by
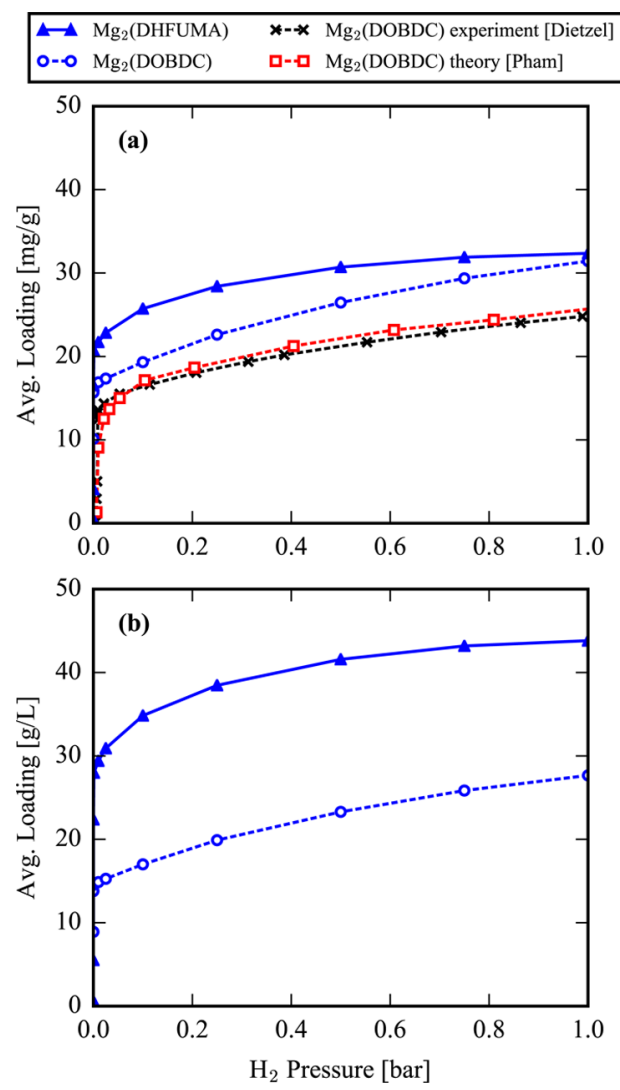

Figure 2. $\mathrm{H}_{2}$ isotherms computed at $T=77 \mathrm{~K}$. (a) $\mathrm{Mg}_{2}$ (DOBDC) isotherms computed in this work, by Pham et al. (extracted from ref 40), and measured by Dietzel et al. (extracted from ref 69) and the predicted $\mathrm{Mg}_{2}$ (DHFUMA) assuming a transferable force field. Isotherms are in units of amount adsorbed per framework mass. (b) $\mathrm{Mg}_{2}$ (DHFUMA) and $\mathrm{Mg}_{2}$ (DOBDC) simulated isotherms from this work in units of amount adsorbed per framework volume.

the experimental results and simulated by Pham et al. which we further discuss in the Supporting Information.

Since the weight compositions of Mg in DHFUMA (25.2 wt $\%)$ and DOBDC (20.0 wt \%) differ slightly, the amount of $\mathrm{H}_{2}$ loaded per framework weight in DHFUMA is marginally better than DOBDC at low pressure but does not represent a remarkable improvement as shown in Figure 2(a). The strong $\mathrm{H}_{2}$-open metal site interactions dominate the adsorption at low temperatures and pressures, and weak $\mathrm{H}_{2}-\mathrm{H}_{2}$ interactions are not sufficient to provide the strong cooperative binding effects observed with $\mathrm{CO}_{2}$ which are later discussed in the section on enhanced $\mathrm{CO}_{2}$ heat of adsorption. In other words, $\mathrm{H}_{2}$ gravimetric adsorption is not significantly improved in DHFUMA at low pressures, and the framework displays $\mathrm{H}_{2}$ saturation behavior at significantly lower pressures than in DOBDC as one would expect from the reduced channel volume. Nevertheless, the advantage of $\mathrm{Mg}_{2}$ (DHFUMA) for $\mathrm{H}_{2}$ storage lies exactly in this reduced channel volume and the doubling of volumetric open metal site density. As can be seen from Figure 2(b), the $\mathrm{H}_{2}$ storage capacity on a volumetric basis (in which the amount loaded is expressed per total volume of adsorbent) is approximately twice that of $\mathrm{Mg}_{2}$ (DOBDC). Not only would a $\mathrm{Mg}_{2}$ (DHFUMA)-based storage device require half the volume to achieve approximately the same $\mathrm{H}_{2}$ storage by weight percent but also the ligand is drastically cheaper. At the cryogenic temperature of $77 \mathrm{~K}$ and extremeley low pressure 
of 0.5 bar, $\mathrm{Mg}_{2}$ (DHFUMA) is predicted to achieve a volumetric uptake of $41.5 \mathrm{~g} \mathrm{H}_{2} / \mathrm{L}$ which is sufficient to surpass the DOE's $2020 \mathrm{H}_{2}$ volumetric storage target of $40 \mathrm{~g} \mathrm{H}_{2} / \mathrm{L}$. We note that Mn-BTT (BTT ${ }^{3-}=1,3,5$-benzenetristetrazolate), one of the best performing MOFs for volumetric hydrogen uptake, has been reported to achieve uptake of $43 \mathrm{~g} \mathrm{H}_{2} / \mathrm{L}$ but at the higher pressure of 1.2 bar. $^{4}$

DFT Predicted Binding Geometries and Energies. We list our calculated lattice parameters of the all the MOFs considered in this work in Table 2 , and we compare the data on

Table 2. Lattice Parameters (in $\AA$ ) of $\mathbf{M}_{2}(\mathrm{DOBDC})$ and $M_{2}$ (DHFUMA) from Theory and Experiment

\begin{tabular}{|c|c|c|c|c|c|c|c|}
\hline \multirow[b]{2}{*}{ metal } & \multicolumn{2}{|c|}{$\begin{array}{l}\text { DHFUMA } \\
\text { (theory) }\end{array}$} & \multicolumn{2}{|c|}{$\begin{array}{l}\text { DOBDC } \\
\text { (theory) }\end{array}$} & \multicolumn{2}{|c|}{ DOBDC (expt) } & \multirow{2}{*}{$\frac{a / a^{\prime}}{\text { (theory) }}$} \\
\hline & $a$ & $c$ & $a^{\prime}$ & $c^{\prime}$ & $a^{\prime}$ & $c^{\prime}$ & \\
\hline $\mathrm{Mg}$ & 18.86 & 6.88 & 26.17 & 6.95 & 25.89 & 6.87 & $72 \%$ \\
\hline $\mathrm{Mn}$ & 18.70 & 7.14 & 26.22 & 7.01 & 26.23 & 7.04 & $71 \%$ \\
\hline $\mathrm{Fe}$ & 18.93 & 6.75 & 26.11 & 6.85 & 26.10 & 6.85 & $73 \%$ \\
\hline Co & 18.67 & 6.77 & 25.91 & 6.82 & 25.89 & 6.81 & $72 \%$ \\
\hline $\mathrm{Ni}$ & 18.59 & 6.65 & 25.73 & 6.75 & 25.72 & 6.74 & $72 \%$ \\
\hline $\mathrm{Cu}$ & 18.85 & 6.13 & 25.84 & 6.29 & 26.00 & 6.26 & $73 \%$ \\
\hline $\mathrm{Zn}$ & 19.01 & 6.72 & 26.18 & 6.88 & 25.93 & 6.84 & $73 \%$ \\
\hline
\end{tabular}

$\mathrm{M}_{2}$ (DOBDC) with available experimental results (taken from ref 36; see references therein) from which we find that the errors of our theoretically predicted lattice parameters of $\mathrm{M}_{2}$ (DOBDC) are within $\sim 1 \%$. We also find that for the same metal the $a$ lattice parameter of $\mathrm{M}_{2}$ (DHFUMA) is proportionally smaller than that of $\mathrm{M}_{2}(\mathrm{DOBDC})$ by $27-29 \%$, and the $c$ lattice parameter of $\mathrm{M}_{2}$ (DHFUMA) is almost the same as that of $\mathrm{M}_{2}$ (DOBDC), with the biggest difference to be only $0.16 \AA$ $(\mathrm{Cu}$ and $\mathrm{Zn})$. Indeed, the decreased unit cell volume of $\mathrm{M}_{2}$ (DHFUMA), i.e., by $\sim 50 \%$ in comparison with $\mathrm{M}_{2}$ (DOBDC), is mainly due to the shortening of the lattice parameter along the $a$ and $b$ axes, and a direct result of that is the doubling of the density of open metal sites. We will see that the shortening of the $a$ lattice parameter and the doubling of the density of open metal sites in $\mathrm{M}_{2}$ (DHFUMA) have a significant effect on the optimal binding configuration of $\mathrm{CO}_{2}$ in $\mathrm{M}_{2}$ (DHFUMA).

Taking $\mathrm{Mg}$ as an example, we show our theoretical optimized binding configuration of $\mathrm{CO}_{2}$ in $\mathrm{Mg}_{2}$ (DOBDC) and $\mathrm{Mg}_{2}$ (DHFUMA) in Figures $3 \mathrm{a}$ and $3 \mathrm{~b}$, respectively. From Figure 3, we can find that a single $\mathrm{CO}_{2}$ molecule has very different binding modes in $\mathrm{Mg}_{2}$ (DOBDC) and $\mathrm{Mg}_{2}$ (DHFUMA). In $\mathrm{Mg}_{2}$ (DOBDC), one terminal oxygen of $\mathrm{CO}_{2}$ binds to $\mathrm{Mg}$ of $\mathrm{Mg}_{2}$ (DOBDC) with a short binding distance of $2.33 \AA$, while the other terminal oxygen of $\mathrm{CO}_{2}$ is aligned with the DOBDC linker and points toward the open pore space of $\mathrm{Mg}_{2}$ (DOBDC). However, in $\mathrm{Mg}_{2}$ (DHFUMA), because of the much shorter interchain $\mathrm{Mg} \cdots \mathrm{Mg}$ distance (i.e., $6.03 \AA$ in comparison with $8.26 \AA$ in $\mathrm{Mg}_{2}(\mathrm{DOBDC})$ ), both terminal oxygens of $\mathrm{CO}_{2}$ are able to bind to two neighboring $\mathrm{Mg}^{2+}$ cations simultaneously, with similar binding distances (i.e., 2.59-2.60 A). Such a unique binding mode results in a much enhanced binding energy of $\mathrm{CO}_{2}$ in $\mathrm{Mg}_{2}$ (DHFUMA), i.e., $50.1 \mathrm{~kJ} / \mathrm{mol}$, which is $20 \%(8.8 \mathrm{~kJ} / \mathrm{mol})$ stronger than that in $\mathrm{Mg}_{2}$ (DOBDC). We show a detailed comparison of the binding energies and relevant $\mathrm{O} \cdots \mathrm{M}$ binding distances of $\mathrm{CO}_{2}$ in $\mathrm{M}_{2}$ (DOBDC) and $\mathrm{M}_{2}$ (DHFUMA) with different metals in Table 3 , in which we also list available experimental data on
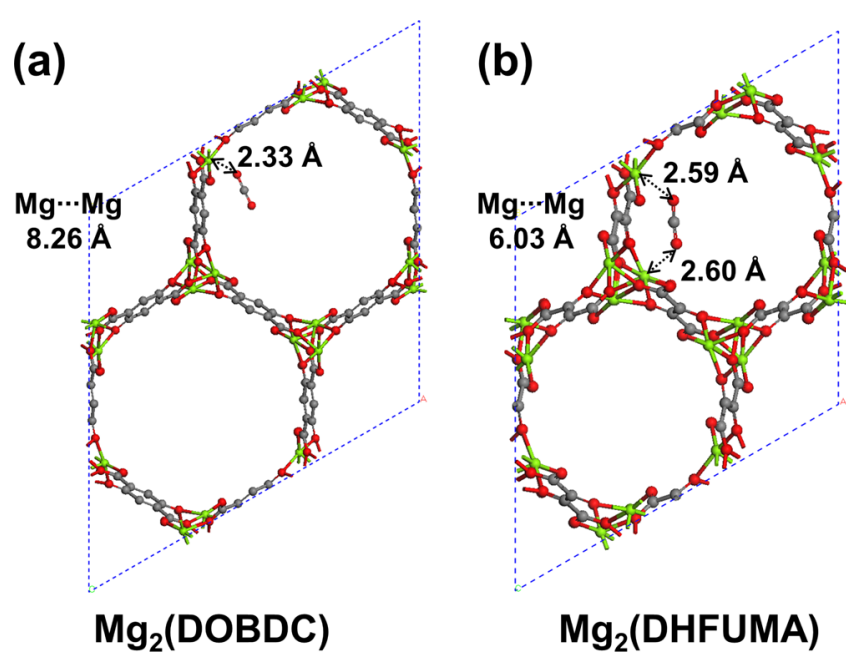

Figure 3. DFT optimized binding configurations of $\mathrm{CO}_{2}$ in (a) $\mathrm{Mg}_{2}$ (DOBDC) and (b) $\mathrm{Mg}_{2}$ (DHFUMA).

Table 3. Binding Energies (in $\mathrm{kJ} / \mathrm{mol}$ ) and Relevant $\mathrm{O} \cdots \mathrm{M}$ Binding Distances (in $\AA$ ) of $\mathrm{CO}_{2}$ in $\mathrm{M}_{2}$ (DOBDC) and $\mathrm{M}_{2}$ (DHFUMA) from Theory and Experiment

\begin{tabular}{|c|c|c|c|c|c|c|c|}
\hline \multirow[b]{2}{*}{ metal } & \multicolumn{2}{|c|}{ DHFUMA (theory) } & \multicolumn{2}{|c|}{$\begin{array}{l}\text { DOBDC } \\
\text { (theory) }\end{array}$} & \multicolumn{2}{|c|}{$\begin{array}{c}\text { DOBDC } \\
(\text { expt) }\end{array}$} & \multirow{2}{*}{$\frac{E_{\mathrm{b}}-E_{\mathrm{b}}^{\prime}}{\text { (theory) }}$} \\
\hline & $E_{\mathrm{b}}$ & $d_{\mathrm{O} \cdots \mathrm{M}}$ & $E_{\mathrm{b}}^{\prime}$ & $d_{\mathrm{O} \cdots \mathrm{M}}^{\prime}$ & $E_{\mathrm{b}}^{\prime}$ & $d_{\mathrm{O} \cdots \mathrm{M}}^{\prime}$ & \\
\hline $\mathrm{Mg}$ & 50.1 & $2.59 / 2.60$ & 41.3 & 2.33 & 43.5 & 2.27 & 8.8 \\
\hline $\mathrm{Mn}$ & 40.5 & $2.64 / 2.75$ & 29.2 & 2.57 & 31.7 & 2.51 & 11.3 \\
\hline $\mathrm{Fe}$ & 40.9 & $2.56 / 2.76$ & 30.0 & 2.43 & 33.2 & 2.29 & 10.9 \\
\hline Co & 41.1 & $2.49 / 2.79$ & 29.3 & 2.43 & 33.6 & 2.23 & 11.8 \\
\hline $\mathrm{Ni}$ & 46.1 & $2.46 / 2.69$ & 34.8 & 2.32 & 38.6 & 2.29 & 11.3 \\
\hline $\mathrm{Cu}$ & 32.0 & $2.69 / 2.80$ & 19.9 & 2.74 & 22.1 & 2.86 & 12.1 \\
\hline $\mathrm{Zn}$ & 37.6 & $2.76 / 2.83$ & 31.3 & 2.66 & 26.8 & 2.43 & 6.3 \\
\hline
\end{tabular}

$\mathrm{CO}_{2}$ adsorption in $\mathrm{M}_{2}$ (DOBDC).$^{70}$ We further looked at the adsorption of a single $\mathrm{H}_{2} \mathrm{O}$ molecule in both $\mathrm{M}_{2}$ (DOBDC) and $\mathrm{M}_{2}$ (DHFUMA) with different metals, and we show a detailed comparison of the binding energies and relevant $\mathrm{O} \cdots \mathrm{M}$ binding distances in Table 4. Interestingly, the binding energies of a

Table 4. Binding Energies (in $\mathrm{kJ} / \mathrm{mol}$ ) and Relevant $\mathrm{O} \cdots \mathrm{M}$ Binding Distances (in $\AA$ ) of $\mathrm{H}_{2} \mathrm{O}$ in $\mathrm{M}_{2}(\mathrm{DOBDC})$ and $\mathrm{M}_{2}$ (DHFUMA) from Theory

\begin{tabular}{cccccc} 
& \multicolumn{2}{c}{ DHFUMA (theory) } & & \multicolumn{2}{c}{ DOBDC (theory) } \\
\cline { 2 - 3 } \cline { 5 - 6 } metal & $E_{\mathrm{b}}$ & $d_{\mathrm{O} \cdot \cdot \mathrm{M}}$ & & $E_{\mathrm{b}}^{\prime}$ & $d_{\mathrm{O} \cdots \mathrm{M}}^{\prime}$ \\
$\mathrm{Mg}$ & 87.4 & 2.19 & & 88.6 & 2.16 \\
$\mathrm{Mn}$ & 73.5 & 2.26 & & 73.3 & 2.29 \\
$\mathrm{Fe}$ & 77.5 & 2.20 & & 77.1 & 2.21 \\
$\mathrm{Co}$ & 79.4 & 2.17 & & 78.9 & 2.17 \\
$\mathrm{Ni}$ & 89.2 & 2.12 & & 89.4 & 2.11 \\
$\mathrm{Cu}$ & 68.1 & 2.22 & & 62.5 & 2.24 \\
$\mathrm{Zn}$ & 74.9 & 2.22 & & 68.4 & 2.23 \\
\hline
\end{tabular}

single $\mathrm{H}_{2} \mathrm{O}$ molecule in $\mathrm{M}_{2}$ (DOBDC) and $\mathrm{M}_{2}$ (DHFUMA) with the same metal are almost identical. Taking $\mathrm{Mg}$ as an example, the binding energies of $\mathrm{H}_{2} \mathrm{O}$ are 88.6 and $87.4 \mathrm{~kJ} / \mathrm{mol}$ in $\mathrm{Mg}_{2}$ (DOBDC) and $\mathrm{Mg}_{2}$ (DHFUMA), respectively. This is because $\mathrm{H}_{2} \mathrm{O}$ has only one central oxygen, and it interacts with both $\mathrm{Mg}_{2}$ (DOBDC) and $\mathrm{Mg}_{2}$ (DHFUMA) through a singlecontact $\mathrm{O} \cdots \mathrm{Mg}$ interaction. Comparing the whole series of $\mathrm{CO}_{2}$ and $\mathrm{H}_{2} \mathrm{O}$ adsorption in $\mathrm{M}_{2}$ (DOBDC) and $\mathrm{M}_{2}$ (DHFUMA) 
with different metals, we can find that the trend is the same; $\mathrm{CO}_{2}$ tends to have much stronger binding in $\mathrm{M}_{2}$ (DHFUMA) than that in $\mathrm{M}_{2}$ (DOBDC) with the same metal, while $\mathrm{H}_{2} \mathrm{O}$ tends to have almost the same binding strength in $\mathrm{M}_{2}$ (DHFUMA) and $\mathrm{M}_{2}$ (DOBDC) with the same metal. This would lead to improved selectivity of $\mathrm{CO}_{2}$ in a $\mathrm{CO}_{2}: \mathrm{H}_{2} \mathrm{O}$ mixture in $\mathrm{M}_{2}$ (DHFUMA) than that in $\mathrm{M}_{2}$ (DOBDC).

Enhanced $\mathrm{CO}_{2}$ Adsorption. We demonstrate in the Supporting Information that the force field of Mercado can reproduce the $a b$ initio potential energy landscape of $\mathrm{CO}_{2}$ in our set of analogues as shown by the agreement of both binding energies and binding geometries. With confirmation of the force field's tranferability, Henry coefficients of the $\mathrm{M}_{2}$ (DOBDC) and $\mathrm{M}_{2}$ (DHFUMA) structures were computed at temperatures of 313.0 and $400.0 \mathrm{~K}$, shown in Table 5. An

Table 5. Henry Coefficients $\left(K_{\mathrm{H}}\right) \times 10^{-3}[\mathrm{~mol} / \mathrm{kg} / \mathrm{Pa}]$ of $\mathrm{CO}_{2}$ in the $\mathrm{M}_{2}$ (DHFUMA) vs $\mathrm{M}_{2}$ (DOBDC) Series at 313 and $400 \mathrm{~K}$

\begin{tabular}{cccccc} 
& \multicolumn{2}{c}{ DHFUMA } & & \multicolumn{2}{c}{ DOBDC } \\
\cline { 2 - 3 } \cline { 5 - 6 } metal & $313 \mathrm{~K}$ & $400 \mathrm{~K}$ & & $313 \mathrm{~K}$ & $400 \mathrm{~K}$ \\
$\mathrm{Mg}$ & 10.7 & 0.22 & & 1.56 & 0.064 \\
$\mathrm{Fe}$ & 1.8 & 0.07 & & 0.20 & 0.017 \\
$\mathrm{Co}$ & 3.2 & 0.11 & & 0.26 & 0.021 \\
$\mathrm{Ni}$ & 3.0 & 0.12 & & 0.27 & 0.021 \\
$\mathrm{Zn}$ & 0.39 & 0.028 & & 0.076 & 0.009 \\
\hline
\end{tabular}

order of magnitude increase is observed in DHFUMA structures over DOBDC structures for a given metal substitution. It is also worthwhile to note that, for a given metal substitution, the $\mathrm{M}_{2}$ (DHFUMA) structure achieves the same order of magnitude (and only slightly lower) Henry coefficient at $400 \mathrm{~K}$ as its DOBDC counterpart at $313 \mathrm{~K}$ in all frameworks except for the $\mathrm{Mg}$ analogues. This large decrease in the free energy of a single adsorbed $\mathrm{CO}_{2}$ molecule in DHFUMA is a direct result of the decreased potential energy of the one molecule per two open metal sites binding mode, which has been demonstrated in our DFT optimization and GCMC simulations. GCMC simulations were utilized to simulate the $\mathrm{CO}_{2}$ uptake in $\mathrm{M}_{2}$ (DOBDC) and $\mathrm{M}_{2}$ (DHFUMA) structures and calculate isotherms for each material. The higher density of open metal sites and enhanced binding energy results in larger uptake at low pressures; however, the reduced channel volume results in quicker saturation of the DHFUMA adsorbent. The $\mathrm{CO}_{2}$ isotherms in $\mathrm{Mg}_{2}$ (DOBDC) and $\mathrm{Mg}_{2}$ (DHFUMA) in Figure 4 visualize this trend. Thus, at low pressures DHFUMA performs significantly better in total $\mathrm{CO}_{2}$ uptake but performs worse in total uptake at higher pressures. A detailed view of all $\mathrm{CO}_{2}$ isotherms is provided in the Supporting Information. Due to the favorable enhancement of the binding energy, DHFUMA analogues are able to capture significantly more $\mathrm{CO}_{2}$ in any pressure range relevant to industrial $\mathrm{CO}_{2}$ capture from flue gas where $P_{\mathrm{CO}_{2}}=0.15$ bar. Figure 5 demonstrates the excess amount of $\mathrm{CO}_{2}$ captured by each metal analogue of DHFUMA in comparison to its DOBDC analogues across a pressure range applicable to flue gas conditions. The excess value peaks at low pressures and then quickly drops to large negative values after the DHFUMA framework saturates with $\mathrm{CO}_{2}$. It is also significant that DHFUMA analogues continue to load approximately $2 \mathrm{~mol} / \mathrm{kg}$ more $\mathrm{CO}_{2}$ at an elevated temperature of $400 \mathrm{~K}$ since high-

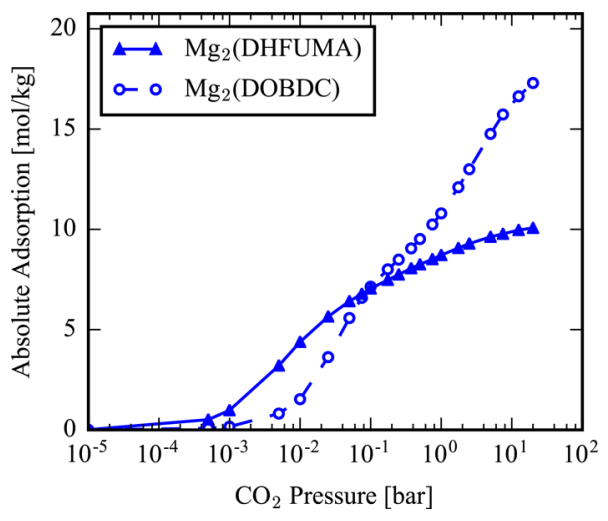

Figure 4. Absolute $\mathrm{CO}_{2}$ adsorption in $\mathrm{Mg}_{2}$ (DHFUMA) vs the absolute $\mathrm{CO}_{2}$ adsorption in $\mathrm{Mg}_{2}$ (DOBDC) at $313 \mathrm{~K}$. The DHFUMA structure significantly outperforms the DOBDC structure in $\mathrm{CO}_{2}$ uptake at low pressures but has far lower capacity of $\mathrm{CO}_{2}$ in the limit of saturation.

temperature adsorption can be used to mitigate competitive water adsorption, as will be seen in later discussion.

Enhanced $\mathrm{CO}_{2}$ Heat of Adsorption. The isosteric heat of adsorption, $\Delta H_{\mathrm{Ads}}$, as a function of loading is a measure of the enthalpy gained on average by adsorbing one additional molecule in the adsorbent system at a specified loading. Conversely, the isosteric heat of desorption, $\Delta H_{\text {Des, }}$ as a function of loading is the amount of enthalpy required to desorb one additional molecule at a specified loading. In Figure 6 we observe an interesting feature of $\mathrm{CO}_{2}$ adsorption in the DHFUMA structure that shows a monotonic increase in the heat of desorption as a function of loading from zero to saturation loading. A molecule that adsorbs when the framework is close to saturation $\left(0.8-0.9 \mathrm{molec} / \mathrm{M}^{2+}\right)$ releases nearly $10 \mathrm{~kJ} / \mathrm{mol}$ more enthalpy than the first molecule to adsorb. In other words, the cooperative binding of $\mathrm{CO}_{2}$ is very strong (due to the proximity of the primary binding sites) and increases in strength monotonically with loading. This leads to the nonintuitive property that the enthalpy penalty to desorb $\mathrm{CO}_{2}$ always decreases as the loading decreases from saturation to empty framework. Notably, $\mathrm{Mg}_{2}$ (DHFUMA) does not exhibit this trend because the binding energy of one $\mathrm{CO}_{2}$ molecule is so strong that cooperative adsorption is only favorable enough to maintain a constant $\Delta H_{\text {Des }}$ as a function of loading. The same phenomenon does not exist with the DOBDC series. Only a $1-2 \mathrm{~kJ} / \mathrm{mol}$ increase in $\Delta H_{\text {Des }}$ is observed in all DOBDC analogues between the limit of 0 loading and the inflection point at 1 molecule per open metal site. Thus, cooperative adsorption at loadings below 1 molecule per open metal site is negligible in the DOBDC frameworks when compared to the DHFUMA frameworks.

Optimizing $\mathrm{CO}_{2}$ Capture in Binary $\mathrm{CO}_{2}: \mathrm{H}_{2} \mathrm{O}$ Mixtures. Enhanced $\mathrm{CO}_{2}$ uptake in the range of partial pressures relevant to adsorption from a coal-fired flue stream does not necessarily indicate an improved potential for industrial-scale $\mathrm{CO}_{2}$ capture. $^{71}$ A multitude of other factors must be considered such as $\mathrm{CO}_{2}: \mathrm{H}_{2} \mathrm{O}$ selectivity, compression work of the $\mathrm{CO}_{2}$ enriched waste stream, and the energy required for adsorbent regeneration, and these attributes can be quantified through a metric known as the parasitic energy. ${ }^{72}$ However, the deleterious effects of water on $\mathrm{CO}_{2}$ uptake are often overlooked when evaluating materials for $\mathrm{CO}_{2}$ capture potential via the parasitic energy. ${ }^{73}$ For this reason we investigated water 

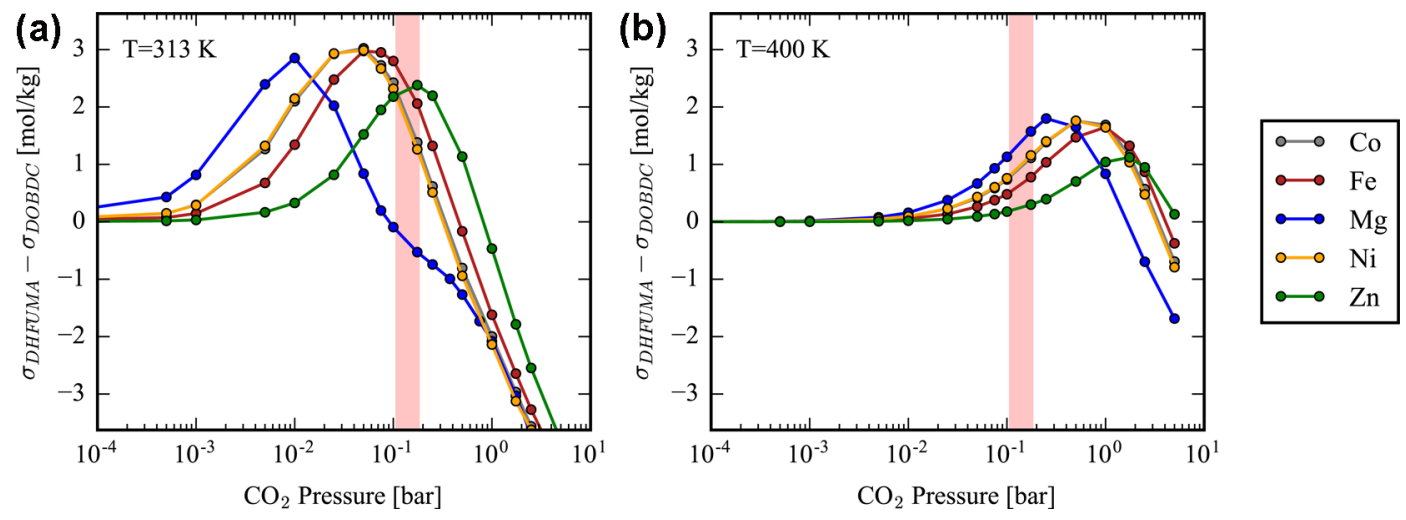

Figure 5. Absolute $\mathrm{CO}_{2}$ adsorption in DHFUMA minus the absolute $\mathrm{CO}_{2}$ adsorption in DOBDC (a) at $313 \mathrm{~K}$ and (b) at $400 \mathrm{~K}$. The pressure region in pink corresponds to the typical partial pressure of $\mathrm{CO}_{2}(P=0.15 \mathrm{bar})$ in the exhaust from a coal-fired power plant. For each metal a temperature exists between 313 and $400 \mathrm{~K}$ which maximizes the excess $\mathrm{CO}_{2}$ uptake in the DHFUMA structure.

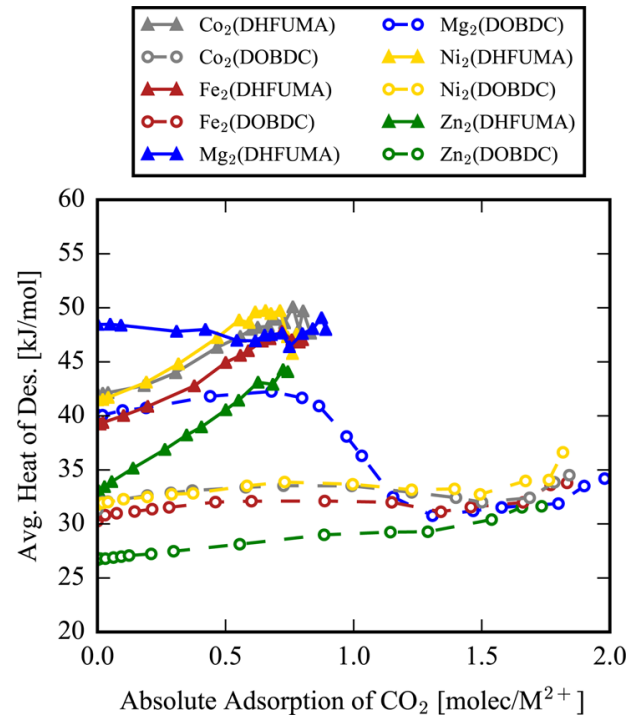

Figure 6. Heat of desorption as a function of loading for the $\mathrm{M}_{2}$ (DOBDC) and $\mathrm{M}_{2}$ (DHFUMA) analogues. The DHFUMA structures, with the exception of the $\mathrm{Mg}$ analogue, exhibit a 7-10 $\mathrm{kJ} / \mathrm{mol}$ increase in the $\Delta H_{\text {Des }}$ between the limit of zero loading and saturation.

adsorption in the DHFUMA and DOBDC series as well since creative strategies such as high-temperature adsorption and low-temperature desorption $\left(\mathrm{HALD}^{74}\right)$ have been proposed to mitigate the parasitic energy when adsorbing $\mathrm{CO}_{2}$ from humid flue gas streams. Pure component water isotherms and binding geometries are shown in the Supporting Information.

More relevant to carbon capture, we performed a $\mathrm{CO}_{2}: \mathrm{H}_{2} \mathrm{O}$ binary mixture analysis to investigate each structure's potential performance for carbon capture in the presence of water. GCMC simulations were performed at a fixed reservoir pressure of 0.15 bar, and the molar composition of $\mathrm{CO}_{2}: \mathrm{H}_{2} \mathrm{O}$ of the reservoir was varied at different temperatures. Note that $\mathrm{N}_{2}$ was not simulated in the mixture as its uptake in the MOF74 framework series has been shown to be negligible in comparison to the uptake of $\mathrm{CO}_{2}$ and $\mathrm{H}_{2} \mathrm{O}$ at flue gas adsorption conditions. ${ }^{38,39}$ The same stepped feature of water adsorption occurs in this binary analysis as in the pure component $\mathrm{H}_{2} \mathrm{O}$ isotherms, and at a certain critical pressure, water condenses within the pore. In the case of this binary mixture analysis, the condensation of $\mathrm{H}_{2} \mathrm{O}$ is sufficient to entirely remove any adsorbed $\mathrm{CO}_{2}$ at equilibrium. Figure 7 demonstrates the loss in $\mathrm{CO}_{2}$ uptake capacity that occurs after the molar composition of water (at fixed total pressure) in the reservoir becomes too high.

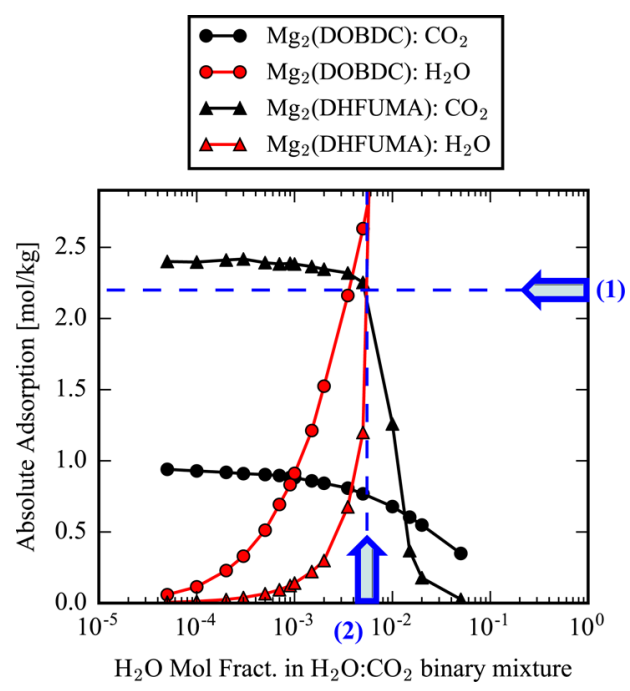

Figure 7. Mixture analysis of $\mathrm{CO}_{2}$ and $\mathrm{H}_{2} \mathrm{O}$ adsorption in the $\mathrm{Mg}$ analogues of DHFUMA and DOBDC. Each data point represents an equilibrated absolute adsorption loading from a GCMC simulation at $400 \mathrm{~K}$ and fixed total pressure of $0.15 \mathrm{bar}$, while the molar composition of $\mathrm{H}_{2} \mathrm{O}$ to $\mathrm{CO}_{2}$ is varied between simulations. For each analogue, two values are extracted, and (1) and (2) demonstrate the values extracted for $\mathrm{Mg}_{2}$ (DHFUMA). (1) Corresponds to the $\mathrm{CO}_{2}$ uptake that is equal to $90 \%$ of the uptake in the limit of 0 mole fraction of $\mathrm{H}_{2} \mathrm{O}$. (2) Corresponds to the $\mathrm{H}_{2} \mathrm{O}$ mole fraction at which the total $\mathrm{CO}_{2}$ uptake has decreased by $10 \%$.

Yet at higher temeprature, the onset of the water step is shifted to a significantly higher mole fraction. A reduction in $\mathrm{CO}_{2}$ uptake capacity follows from this temperature increase, yet this uptake loss is mitigated in the DHFUMA structure due to the enhanced $\mathrm{CO}_{2}$ affinity. An entire summary of the mixture anlaysis for each structure at various temperatures is presented in the Supporting Information. From one mixture analysis at a specified temperature, we can extract two values of importance which are visualized in Figure 7: the water mole fraction just before water condensation occurs and the amount of $\mathrm{CO}_{2}$ loaded at that specific water mole fraction. These represent 
competing process design variables. To increase the water mole fraction at which condensation occurs, we must raise the temperature, which consequently reduces the amount of $\mathrm{CO}_{2}$ loaded. These two quantities are plotted for each analogue structure across a range of adsorption temperatures (313-400 $\mathrm{K}$ for $\mathrm{M}=[\mathrm{Co}, \mathrm{Fe}, \mathrm{Ni}, \mathrm{Zn}]$ and $400-473 \mathrm{~K}$ for $\mathrm{M}=[\mathrm{Mg}])$ in Figure 8. From a carbon capture process design perspective, the

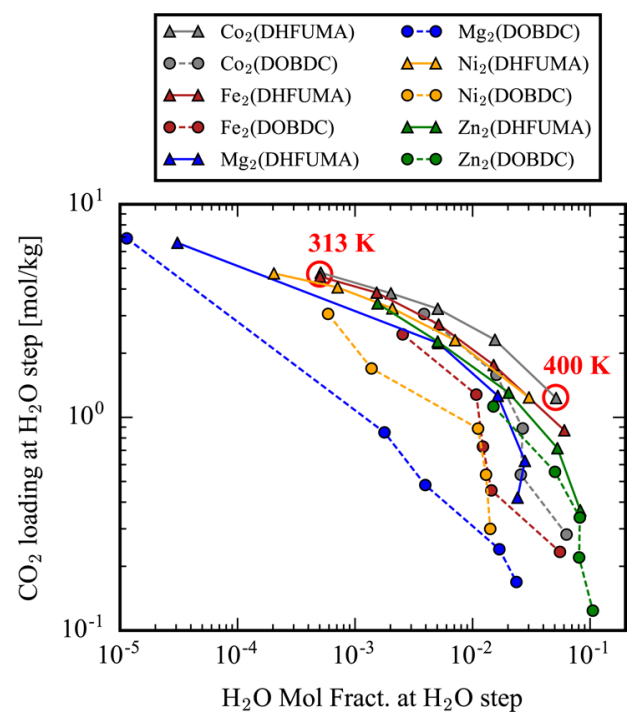

Figure 8. Mixture analysis of all analogues demonstrating the competing nature of $\mathrm{CO}_{2}$ uptake and water tolerance. The $y$-axis corresponds to value (1) extracted from Figure 7 , and the $x$-axis corresponds to value (2). The ideal material for $\mathrm{CO}_{2}$ capture would have a data point corresponding to $313 \mathrm{~K}$ at the top right corner of the plot.

ideal material would be located in the top right corner of Figure 8 where the material loads large amounts of $\mathrm{CO}_{2}$ in the presence of extremely high water mole fractions. Since the $x$ and $y$ quantities of Figure 8 represent competing variables (but we desire to maximize both of them), we can interpret this summary as a problem of Pareto optimality, and a Pareto frontier can be observed for $\mathrm{Co}_{2}$ (DHFUMA). This means that regardless of the adsorption temperature chosen for our capture process there is no material that can simultaneously achieve a higher water tolerance and $\mathrm{CO}_{2}$ uptake capacity at thermodynamic equilibrium than $\mathrm{Co}_{2}$ (DHFUMA). Therefore, regardless of the selected operating temperature, $\mathrm{Co}_{2}$ (DHFUMA) will have the best uptake and water tolerance as is easily visualized in Figure 8. In more physical terms, a Pareto optimal material in this context of $\mathrm{CO}_{2}$ capture in the presence of humidity will be the material which delicately balances two factors. First, $\mathrm{CO}_{2}$ uptake must remain the highest with increasing temperature, which fundamentally arises from the highest $\mathrm{CO}_{2}$ Henry coefficient, which in turn arises from the strength of $\mathrm{CO}_{2}$ interactions at the open metal site(s). Second, $\mathrm{H}_{2} \mathrm{O}$ condensation must occur at the highest water mole fraction, which arises from a combination of the weakest possible $\mathrm{H}_{2} \mathrm{O}$ interactions with the open metal site and the largest pore size. Hence we can see the competing nature of these two factors since the strengths of $\mathrm{CO}_{2}$ binding and $\mathrm{H}_{2} \mathrm{O}$ binding at the open metal site are highly correlated, and the advantage of DHFUMA becomes immediately clear since we selectively strengthen the binding energetics of $\mathrm{CO}_{2}$ across all metals due to the one molecule per two open metal site binding mode.
Thus, we also notably observe that each $\mathrm{M}_{2}$ (DHFUMA) represents a Pareto frontier over its DOBDC counterpart. For example, $\mathrm{Ni}_{2}$ (DOBDC) cannot maximize either water tolerance or $\mathrm{CO}_{2}$ uptake above $\mathrm{Ni}_{2}$ (DHFUMA) regardless of our specification of the adsorption temperature.

\section{CONCLUSIONS}

We have demonstrated the in silico design of a new MOF-74 analogue based on the aliphatic DHFUMA ligand. We predict exceptional small-molecule adsorption properties via a combination of $a b$ initio electronic structure calculations and classical molecular simulation techniques in conjunction with the extensive previous research efforts to create simulation methods that accurately predict guest molecule behavior in MOF-74-type frameworks. Namely we have predicted (1) a doubling of the volumetric storage capacity of $\mathrm{H}_{2}$ in $\mathrm{Mg}_{2}$ (DHFUMA) over $\mathrm{Mg}_{2}$ (DOBDC) at the cryogenic temperature of $77 \mathrm{~K}$ and pressures below 1 bar (and can meet the 2020 DOE target of $40 \mathrm{~g} / \mathrm{L}$ at $\sim 0.5 \mathrm{bar}$ ); (2) a marked enhancement of $\mathrm{CO}_{2}$ uptake in low-pressure regimes over the DOBDC analogue series; and (3) a selective increase of $\mathrm{CO}_{2}$ binding energy (i.e., stronger $\mathrm{CO}_{2}$ binding with no change in $\mathrm{H}_{2} \mathrm{O}$ binding energy), the basis for which we propose an industrial-scale $\mathrm{CO}_{2}$ capture process inspired by the HALD scheme (see the Supporting Information). These enhancements are a direct result of the open metal site properties of the $\mathrm{M}_{2}$ (DHFUMA) frameworks.

This material contains double the volumetric density of open metal sites over DOBDC analogues, leading to a remarkable simulated volumetric $\mathrm{H}_{2}$ storage capacity. Additionally, the distance between two adjacent open metal sites in each channel is reduced from $8.3 \AA$ in DOBDC to $6.0 \AA$ in DHFUMA. $\mathrm{CO}_{2}$ binds to two open metal sites in the $\mathrm{M}_{2}$ (DHFUMA) framework, resulting in a significantly stronger binding energy than in $\mathrm{M}_{2}$ (DOBDC). The confined pore channel results in significant cooperative adsorption of $\mathrm{CO}_{2}$, with an isosteric heat of adsorption that is $\sim 15 \mathrm{~kJ} / \mathrm{mol}$ stronger at saturation than in the limit of zero loading. Furthermore, since $\mathrm{H}_{2} \mathrm{O}$ still can only bind to one open metal site in $\mathrm{M}_{2}$ (DHFUMA), the $a b$ initio calculated quantity of $\Delta E_{\text {bind, } \mathrm{H}_{2} \mathrm{O}}-\Delta E_{\text {bind, } \mathrm{CO}_{2}}$ in the DHFUMA series is typically $\sim 10 \mathrm{~kJ} / \mathrm{mol}$ higher than in the DOBDC series, indicating that the DHFUMA series has more selective $\mathrm{CO}_{2}$ binding energetics relative to $\mathrm{H}_{2} \mathrm{O}$. This enhanced selectivity for $\mathrm{CO}_{2}$ is exploited in our classical GCMC simulations, and adsorption at high temperatures is proposed, allowing for a theoretical process by which $\mathrm{CO}_{2}$ can be captured in appreciable amounts $(\sim 1-2 \mathrm{~mol} / \mathrm{kg})$ in the presence of nontrace amounts of water $(\sim 0.1-1 \mathrm{~mol} \%)$. The water tolerance and amount of $\mathrm{CO}_{2}$ captured is dependent on metal choice and adsorption temperature. Finally, an $80 \%$ decrease in ligand expense (per mol) suggests that an $\mathrm{M}_{2}$ (DHFUMA) analogue may in the future represent an economically improved path forward for large scale $\mathrm{H}_{2}$ storage or $\mathrm{CO}_{2}$ capture from flue gas.

The theoretical work in this paper should motivate efforts to experimentally synthesize $\mathrm{M}_{2}$ (DHFUMA) analogues and confirm our simulated volumetric $\mathrm{H}_{2}$ storage capacity and adsorption behavior of $\mathrm{CO}_{2}: \mathrm{H}_{2} \mathrm{O}$ mixtures. We note the synthesis of $\mathrm{M}_{2}(\mathrm{DOBDC})$ is usually very challenging. ${ }^{31}$ Thus far, our efforts to synthesize $\mathrm{M}_{2}$ (DHFUMA) are unsuccessful. However, we do not see any obvious reason why $\mathrm{M}_{2}$ (DHFUMA) cannot be synthesized experimentally, consid- 
ering the dynamical and mechanical stabilities of these materials as well as the availabilities and chemical stabilities of the metal and organic precursors. We also believe this framework could be useful for a variety of other separations or storage applications relevant to clean energy. In the future we plan to investigate a range of topics such as selective adsorption of components from light olefin mixtures which are small enough to fit into the DHFUMA channel network if the material can be synthesized.

\section{ASSOCIATED CONTENT}

\section{S Supporting Information}

The Supporting Information is available free of charge on the ACS Publications website at DOI: 10.1021/acs.jpcc.6b10363.

Crystallographic data for $\mathrm{Mg}_{2}(\mathrm{DOBDC})$ and $\mathrm{Mg}_{2}$ (DHFUMA) (ZIP)

Additional computational details; calculated vibrational frequencies and elastic constants of $\mathrm{Mg}_{2}$ (DHFUMA); structure files and charges; additional crystallographic data; force field parametrization details; $\mathrm{CO}_{2}$ force field transferability; $\mathrm{CO}_{2}$ isotherms; $\mathrm{H}_{2} \mathrm{O}$ isotherms; $\mathrm{H}_{2} \mathrm{O}: \mathrm{CO}_{2}$ mixture analysis; attempted synthetic procedures (PDF)

\section{AUTHOR INFORMATION}

\section{Corresponding Author}

*E-mail: mharanczyk@lbl.gov.

ORCID ${ }^{\circ}$

Sanliang Ling: 0000-0003-1574-7476

Kyriakos C. Stylianou: 0000-0003-1670-0020

Berend Smit: 0000-0003-4653-8562

\section{Author Contributions}

${ }^{\#}$ M.W. and S.L. contributed equally to this work

Notes

The authors declare no competing financial interest.

\section{ACKNOWLEDGMENTS}

M.W. and B. Smit were supported by the Center for Gas Separations Relevant to Clean Energy Technologies, an Energy Frontier Research Center funded by the U.S. Department of Energy, Office of Science, Basic Energy Sciences under Award \# DE-SC0001015 for studies on statistical thermodynamic predictions of adsorption and in silico MOF assembly. B. Smit's research has received funding from the European Research Council (ERC) under the European Union's Horizon 2020 research and innovation programme (grant agreement No 666983, MaGic). S.L. and B. Slater were supported by EPSRC (EP/K039296/1 and EP/K038400/1) for studies on electronic structure calculations. M.H. was supported by the U.S. Department of Energy, Office of Basic Energy Sciences, Division of Chemical Sciences, Geosciences and Biosciences under Award DE-FG02-12ER16362 for studies on cheminformatic approaches to linker identification, and the Center for Advanced Mathematics for Energy Research Applications for the development of algorithms of structure assembly. K.S. was supported by the Swiss National Science Foundation (SNSF) with funding under the Ambizione Energy Grant n.PZENP2_166888 for studies on experimental synthesis. This research used resources of the National Energy Research Scientific Computing Center (NERSC), which is supported by the Office of Science of the U.S. Department of Energy under
Contract No. DE-AC02-05CH11231. Part of the computational work was performed on ARCHER through our membership of the HPC Materials Chemistry Consortium funded by EPSRC (EP/L000202). S.L. thanks Furio Cora for help on CRYSTAL calculations.

\section{REFERENCES}

(1) Zhou, H. C.; Long, J. R.; Yaghi, O. M. Introduction to MetalOrganic Frameworks. Chem. Rev. 2012, 112, 673-674.

(2) Liu, J.; Thallapally, P. K.; McGrail, B. P.; Brown, D. R.; Liu, J. Progress in Adsorption-Based $\mathrm{CO}_{2}$ Capture by Metal-Organic Frameworks. Chem. Soc. Rev. 2012, 41, 2308-2322.

(3) Mason, J. A.; Veenstra, M.; Long, J. R. Evaluating Metal-Organic Frameworks for Natural Gas Storage. Chem. Sci. 2014, 5, 32-51.

(4) Murray, L. J.; Dinca, M.; Long, J. R. Hydrogen Storage in MetalOrganic Frameworks. Chem. Soc. Rev. 2009, 38, 1294-1314.

(5) Kreno, L. E.; Leong, K.; Farha, O. K.; Allendorf, M.; Van Duyne, R. P.; Hupp, J. T. Metal-Organic Framework Materials as Chemical Sensors. Chem. Rev. 2012, 112, 1105-1125.

(6) Ranocchiari, M.; van Bokhoven, J. A. Catalysis by Metal-Organic Frameworks: Fundamentals and Opportunities. Phys. Chem. Chem. Phys. 2011, 13, 6388-6396.

(7) Li, J.-R.; Sculley, J.; Zhou, H.-C. Metal-Organic Frameworks for Separations. Chem. Rev. 2012, 112, 869-932.

(8) Yaghi, O. M.; O’Keeffe, M.; Ockwig, N. W.; Chae, H. K.; Eddaoudi, M.; Kim, J. Reticular Synthesis and the Design of New Materials. Nature 2003, 423, 705-714.

(9) Xiang, S.-C.; Zhang, Z.; Zhao, C.-G.; Hong, K.; Zhao, X.; Ding, D.-R.; Xie, M.-H.; Wu, C.-D.; Das, M. C.; Gill, R.; et al. Rationally Tuned Micropores Within Enantiopure Metal-Organic Frameworks for Highly Selective Separation of Acetylene and Ethylene. Nat. Commun. 2011, 2, 204.

(10) Dawson, R.; Adams, D. J.; Cooper, A. I. Chemical Tuning of $\mathrm{CO}_{2}$ Sorption in Robust Nanoporous Organic Polymers. Chem. Sci. 2011, 2, 1173-1177.

(11) Das, M. C.; Guo, Q.; He, Y.; Kim, J.; Zhao, C. G.; Hong, K.; Xiang, S.; Zhang, Z.; Thomas, K. M.; Krishna, R; et al. Interplay of Metalloligand and Organic Ligand to Tune Micropores Within Isostructural Mixed-Metal Organic Frameworks (M'MOFs) for Their Highly Selective Separation of Chiral and Achiral Small Mol. J. Am. Chem. Soc. 2012, 134, 8703-8710.

(12) Böhme, U.; Barth, B.; Paula, C.; Kuhnt, A.; Schwieger, W.; Mundstock, A.; Caro, J.; Hartmann, M. Ethene/Ethane and Propene/ Propane Separation via the Olefin and Paraffin Selective MetalOrganic Framework Adsorbents CPO-27 and ZIF-8. Langmuir 2013, $29,8592-8600$.

(13) Mason, J. A.; Oktawiec, J.; Taylor, M. K.; Hudson, M. R.; Rodriguez, J.; Bachman, J. E.; Gonzalez, M. I.; Cervellino, A.; Guagliardi, A.; Brown, C. M.; et al. Methane Storage in Flexible Metal-Organic Frameworks With Intrinsic Thermal Management. Nature 2015, 527, 357-361.

(14) Cui, X.; Chen, K.; Xing, H.; Yang, Q.; Krishna, R.; Bao, Z.; Wu, H.; Zhou, W.; Dong, X.; Han, Y.; et al. Pore Chemistry and Size Control in Hybrid Porous Materials for Acetylene Capture From Ethylene. Science 2016, 353, 141-144.

(15) Caskey, S. R.; Wong-Foy, A. G.; Matzger, A. J. Dramatic Tuning of Carbon Dioxide Uptake via Metal Substitution in a Coordination Polymer With Cylindrical Pores. J. Am. Chem. Soc. 2008, 130, 1087010871.

(16) Mason, J. A.; Sumida, K.; Herm, Z. R.; Krishna, R.; Long, J. R. Evaluating Metal-Organic Frameworks for Post-Combustion Carbon Dioxide Capture via Temperature Swing Adsorption. Energy Environ. Sci. 2011, 4, 3030-3040.

(17) Wong-Foy, A. G.; Matzger, A. J.; Yaghi, O. M. Exceptional $\mathrm{H}_{2}$ Saturation Uptake in Microporous Metal-Organic Frameworks. J. Am. Chem. Soc. 2006, 128, 3494-3495.

(18) Cook, T. R.; Zheng, Y. R.; Stang, P. J. Metal-Organic Frameworks and Self-Assembled Supramolecular Coordination 
Complexes: Comparing and Contrasting the Design, Synthesis, and Functionality of Metal-Organic Materials. Chem. Rev. 2013, 113, 734777.

(19) Xue, M.; Liu, Y.; Schaffino, R. M.; Xiang, S.; Zhao, X.; Zhu, G. S.; Qiu, S. L.; Chen, B. New Prototype Isoreticular Metal-Organic Framework $\mathrm{Zn}_{4} \mathrm{O}(\mathrm{FMA})_{3}$ for Gas Storage. Inorg. Chem. 2009, 48, 4649-4651.

(20) Mueller, U.; Luinstra, G.; Yaghi, O. M. US Pat.6 617 467. 2004; BASF Aktiengesellschaft.

(21) Rood, J. A.; Noll, B. C.; Henderson, K. W.; Dame, N. Synthesis, Structural Characterization, Gas Sorption and Guest-Exchange Studies of the Lightweight, Porous Metal-Organic Framework $\alpha$ $\left[\mathrm{Mg}_{3}\left(\mathrm{O}_{2} \mathrm{CH}\right)_{6}\right]$. Inorg. Chem. 2006, 45, 5521-5528.

(22) Alvarez, E.; Guillou, N.; Martineau, C.; Bueken, B.; Vandevoorde, B.; Leguillouzer, C.; Fabry, P.; Nouar, F.; Taulelle, F.; Devos, D.; et al. The Structure of the Aluminum Fumarate MetalOrganic Framework A520. Angew. Chem., Int. Ed. 2015, 54, 36643668.

(23) Deng, H.; Grunder, S.; Cordova, K. E.; Valente, C.; Furukawa, H.; Hmadeh, M.; Gandara, F.; Whalley, A. C.; Liu, Z.; Asahina, S.; et al. Large-Pore Apertures in a Series of Metal-Organic Frameworks. Science 2012, 336, 1018-1023.

(24) Witman, M.; Ling, S.; Anderson, S.; Tong, L.; Stylianou, K.; Slater, B.; Smit, B.; Haranczyk, M. In Silico Design and Screening of Hypothetical MOF-74 Analogs and Their Experimental Synthesis. Chem. Sci. 2016, 7, 6263-6272.

(25) Wilmer, C. E.; Leaf, M.; Lee, C. Y.; Farha, O. K.; Hauser, B. G.; Hupp, J. T.; Snurr, R. Q. Large-Scale Screening of Hypothetical Metal-Organic Frameworks. Nat. Chem. 2011, 4, 83-89.

(26) Martin, R. L.; Lin, L. C.; Jariwala, K.; Smit, B.; Haranczyk, M. Mail-Order Metal-Organic Frameworks (MOFs): Designing Isoreticular MOF-5 Analogues Comprising Commercially Available Organic Molecules. J. Phys. Chem. C 2013, 117, 12159-12167.

(27) Martin, R. L.; Haranczyk, M. Construction and Characterization of Structure Models of Crystalline Porous Polymers. Cryst. Growth Des. 2014, 14, 2431-2440.

(28) Addicoat, M. A.; Coupry, D. E.; Heine, T. AuToGraFS: Automatic Topological Generator for Framework Structures. J. Phys. Chem. A 2014, 118, 9607-9614.

(29) Boyd, P. G.; Woo, T. K. A Generalized Method for Constructing Hypothetical Nanoporous Materials of Any Net Topology From Graph Theory. CrystEngComm 2016, 18, 3777-3792. (30) Rosi, N. L.; Kim, J.; Eddaoudi, M.; Chen, B.; Keeffe, M. O.; Yaghi, O. M. Rod Packings and Metal-Organic Frameworks Constructed From Rod-Shaped Secondary Building Units Rod Packings and Metal-Organic Frameworks Constructed From RodShaped Secondary Building Units. J. Am. Chem. Soc. 2005, 127, 15041518.

(31) Lee, K.; Isley, W. C.; Dzubak, A. L.; Verma, P.; Stoneburner, S. J.; Lin, L.-C.; Howe, J. D.; Bloch, E. D.; Reed, D. A.; Hudson, M. R.; et al. Design of a Metal-Organic Framework With Enhanced Back Bonding for Separation of $\mathrm{N}_{2}$ and $\mathrm{CH}_{4}$. J. Am. Chem. Soc. 2014, 136, 698-704.

(32) Wang, L. J.; Deng, H.; Furukawa, H.; Gándara, F.; Cordova, K. E.; Peri, D.; Yaghi, O. M. Synthesis and Characterization of MetalOrganic Framework-74 Containing 2, 4, 6, 8, and 10 Different Metals. Inorg. Chem. 2014, 53, 5881-5883.

(33) Kapelewski, M. T.; Geier, S. J.; Hudson, M. R.; Stück, D.; Mason, J. A.; Nelson, J. N.; Xiao, D. J.; Hulvey, Z.; Gilmour, E.; FitzGerald, S. A.; et al. $\mathrm{M}_{2}(\mathrm{~m}-\mathrm{Dobdc})(\mathrm{M}=\mathrm{Mg}, \mathrm{Mn}, \mathrm{Fe}, \mathrm{Co}, \mathrm{Ni})$ Metal-Organic Frameworks Exhibiting Increased Charge Density and Enhanced $\mathrm{H}_{2}$ Binding at the Open Metal Sites. J. Am. Chem. Soc. 2014, 136, 12119-12129.

(34) McDonald, T. M.; Mason, J. A.; Kong, X.; Bloch, E. D.; Gygi, D.; Dani, A.; Crocellà, V.; Giordanino, F.; Odoh, S. O.; Drisdell, W. S.; et al. Cooperative Insertion of $\mathrm{CO}_{2}$ in Diamine-Appended MetalOrganic Frameworks. Nature 2015, 519, 303-308.

(35) Runčevski, T.; Kapelewski, M. T.; Torres-Gavosto, R. M.; Tarver, J. D.; Brown, C. M.; Long, J. R. Adsorption of Two Gas
Molecules at a Single Metal Site in a Metal-Organic Framework. Chem. Commun. 2016, 52, 8251-8254.

(36) Lee, K.; Howe, J. D.; Lin, L. C.; Smit, B.; Neaton, J. B. SmallMolecule Adsorption in Open-Site Metal-Organic Frameworks: A Systematic Density Functional Theory Study for Rational Design. Chem. Mater. 2015, 27, 668-678.

(37) Lin, L. C.; Lee, K.; Gagliardi, L.; Neaton, J. B.; Smit, B. ForceField Development From Electronic Structure Calculations With Periodic Boundary Conditions: Applications to Gaseous Adsorption and Transport in Metal-Organic Frameworks. J. Chem. Theory Comput. 2014, 10, 1477-1488.

(38) Dzubak, A. L.; Lin, L.-C.; Kim, J.; Swisher, J. A.; Poloni, R.; Maximoff, S. N.; Smit, B.; Gagliardi, L. Ab Initio Carbon Capture in Open-Site Metal-Organic Frameworks. Nat. Chem. 2012, 4, 810-816.

(39) Mercado, R.; Vlaisavljevich, B.; Lin, L.-C.; Lee, K.; Lee, Y.; Mason, J. A.; Xiao, D. J.; Gonzalez, M. I.; Kapelewski, M. T.; Neaton, J. B.; et al. Force Field Development From Periodic Density Functional Theory Calculations for Gas Separation Applications Using MetalOrganic Frameworks. J. Phys. Chem. C 2016, 120, 12590-12604.

(40) Pham, T.; Forrest, K. A.; Mclaughlin, K.; Eckert, J.; Space, B. Capturing the $\mathrm{H}_{2}$-Metal Interaction in Mg-Mof-74 Using Classical Polarization. J. Phys. Chem. C 2014, 118, 22683-22690.

(41) VandeVondele, J.; Krack, M.; Mohamed, F.; Parrinello, M.; Chassaing, T.; Hutter, J. Quickstep: Fast and Accurate Density Functional Calculations Using a Mixed Gaussian and Plane Waves Approach. Comput. Phys. Commun. 2005, 167, 103-128.

(42) Hutter, J.; Iannuzzi, M.; Schiffmann, F.; VandeVondele, J. CP2K: Atomistic Simulations of Condensed Matter Systems. WIREs Comput. Mol. Sci. 2014, 4, 15-25.

(43) Perdew, J. P.; Burke, K.; Ernzerhof, M. Generalized Gradient Approximation Made Simple. Phys. Rev. Lett. 1996, 77, 3865-3868.

(44) Adamo, C.; Barone, V. Toward Reliable Density Functional Methods Without Adjustable Parameters: The PBE0Model. J. Chem. Phys. 1999, 110, 6158.

(45) Ernzerhof, M.; Scuseria, G. E. Assessment of the Perdew-BurkeErnzerhof Exchange-Correlation Functional. J. Chem. Phys. 1999, 110, 5029-5036.

(46) Poloni, R.; Smit, B.; Neaton, J. B. $\mathrm{CO}_{2}$ Capture by MetalOrganic Frameworks With Van Der Waals Density Functionals. J. Phys. Chem. A 2012, 116, 4957-64.

(47) Nazarian, D.; Ganesh, P.; Sholl, D. S. Benchmarking Density Functional Theory Predictions of Framework Structures and Properties in a Chemically Diverse Test Set of Metal-Organic Frameworks. J. Mater. Chem. A 2015, 3, 22432-22440.

(48) Grimme, S.; Antony, J.; Ehrlich, S.; Krieg, H. A Consistent and Accurate $\mathrm{Ab}$ Initio Parametrization of Density Functional Dispersion Correction (DFT-D) for the 94 Elements H-Pu. J. Chem. Phys. 2010, 132, 154104.

(49) Ling, S.; Slater, B. Unusually Large Band Gap Changes in Breathing Metal-Organic Framework Materials. J. Phys. Chem. C 2015, 119, 16667-16677.

(50) Nanthamathee, C.; Ling, S.; Slater, B.; Attfield, M. P. Contradistinct Thermoresponsive Behavior of Isostructural MIL-53 Type Metal-Organic Frameworks by Modifying the Framework Inorganic Anion. Chem. Mater. 2014, 27, 85-95.

(51) Ling, S.; Slater, B. Dynamic Acidity in Defective UiO-66. Chem. Sci. 2016, 7, 4706-4712.

(52) Guidon, M.; Hutter, J.; Vandevondele, J. Auxiliary Density Matrix Methods for Hartree-Fock Exchange Calculations. J. Chem. Theory Comput. 2010, 6, 2348-2364.

(53) Campañá, C.; Mussard, B.; Woo, T. K. Electrostatic Potential Derived Atomic Charges for Periodic Systems Using a Modified Error Functional. J. Chem. Theory Comput. 2009, 5, 2866-2878.

(54) Golze, D.; Hutter, J.; Iannuzzi, M. Wetting of Water on Hexagonal Boron Nitride@Rh(111): A QM/MM Model Based on Atomic Charges Derived for Nano-Structured Substrates. Phys. Chem. Chem. Phys. 2015, 17, 14307-14316.

(55) Dovesi, R.; Orlando, R; Erba, A.; Zicovich-Wilson, C. M.; Civalleri, B.; Casassa, S.; Maschio, L.; Ferrabone, M.; De La Pierre, M.; 
D'Arco, P.; et al. CRYSTAL14: A Program for the Ab Initio Investigation of Crystalline Solids. Int. J. Quantum Chem. 2014, 114, 1287-1317.

(56) Dovesi, R.; Saunders, V. R.; Roetti, C.; Orlando, R.; ZicovichWilson, C. M.; Pascale, F.; Civalleri, B.; Doll, K.; Harrison, N. M.; Bush, I. J. et al. CRYSTAL14 User's Manual; University of Torino: Torino, 2014; Available at http://www.crystal.unito.it.

(57) Stephens, P. J.; Devlin, F. J.; Chabalowski, C. F.; Frisch, M. J. Ab Initio Calculation of Vibrational Absorption and Circular Dichroism Spectra Using Density Functional Force Fields. J. Phys. Chem. 1994, 98, 11623-11627.

(58) Rappe, A. K.; Casewit, C. J.; Colwell, K. S.; Goddard, W. A., III; Skiff, W. M. UFF, a Full Periodic Table Force Field for Molecular Mechanics and Molecular Dynamics Simulations. J. Am. Chem. Soc. 1992, 114, 10024-10035.

(59) Mayo, S. L.; Olafson, B. D.; Goddard, W. A. DREIDING: A Generic Force Field for Molecular Simulations. J. Phys. Chem. 1990, 94, 8897-8909.

(60) Chen, L.; Morrison, C. A.; Düren, T. Improving Predictions of Gas Adsorption in Metal-Organic Frameworks With Coordinatively Unsaturated Metal Sites: Model Potentials, Ab Initio Parameterization, and GCMC Simulations. J. Phys. Chem. C 2012, 116, 18899-18909.

(61) Wahiduzzaman, M.; Walther, C. F. J.; Heine, T. Hydrogen Adsorption in Metal-Organic Frameworks: The Role of Nuclear Quantum Effects. J. Chem. Phys. 2014, 141, 064708.

(62) Pham, T.; Forrest, K. A.; Banerjee, R.; Orcajo, G.; Eckert, J.; Space, B. Understanding the $\mathrm{H}_{2}$ Sorption Trends in the M-Mof-74 Series ( $\mathrm{M}=\mathrm{Mg}$, Ni, Co, Zn). J. Phys. Chem. C 2015, 119, 1078-1090.

(63) Dubbeldam, D.; Calero, S.; Ellis, D. E.; Snurr, R. Q. RASPA: Molecular Simulation Software for Adsorption and Diffusion in Flexible Nanoporous Materials. Mol. Simul. 2016, 42, 81-101.

(64) Willems, T. F.; Rycroft, C. H.; Kazi, M.; Meza, J. C.; Haranczyk, M. Algorithms and Tools for High-Throughput Geometry-Based Analysis of Crystalline Porous Materials. Microporous Mesoporous Mater. 2012, 149, 134-141.

(65) Pinheiro, M.; Martin, R. L.; Rycroft, C. H.; Haranczyk, M. High Accuracy Geometric Analysis of Crystalline Porous Materials. CrystEngComm 2013, 15, 7531-7538.

(66) Hedman, D.; Reza Barzegar, H.; Rosén, A.; WÅgberg, T.; Andreas Larsson, J. On the Stability and Abundance of Single Walled Carbon Nanotubes. Sci. Rep. 2015, 5, 16850.

(67) Born, M. On the Stability of Crystal Lattices. I. Math. Proc. Cambridge Philos. Soc. 1940, 36, 160-172.

(68) Mouhat, F.; Coudert, F.-X. Necessary and Sufficient Elastic Stability Conditions in Various Crystal Systems. Phys. Rev. B: Condens. Matter Mater. Phys. 2014, 90, 224104.

(69) Dietzel, P. D. C.; Georgiev, P. A.; Eckert, J.; Blom, R.; Strässle, T.; Unruh, T. Interaction of Hydrogen With Accessible Metal Sites in the Metal-Organic Frameworks $\mathrm{M}_{2}$ (dhtp) (CPO-27-M; $\mathrm{M}=\mathrm{Ni}$, Co, $\mathrm{Mg}$ ). Chem. Commun. 2010, 46, 4962-4964.

(70) Queen, W. L.; Hudson, M. R.; Bloch, E. D.; Mason, J. A.; Gonzalez, M. I.; Lee, J. S.; Gygi, D.; Howe, J. D.; Lee, K.; Darwish, T. A.; et al. Comprehensive Study of Carbon Dioxide Adsorption in the Metal-Organic Frameworks $\mathrm{M}_{2}$ (dobdc) $(\mathrm{M}=\mathrm{Mg}, \mathrm{Mn}, \mathrm{Fe}, \mathrm{Co}, \mathrm{Ni}$, $\mathrm{Cu}, \mathrm{Zn})$. Chem. Sci. 2014, 5, 4569-4581.

(71) Smit, B.; Reimer, J. R.; Oldenburg, C. M.; Bourg, I. C. Introduction to Carbon Capture and Sequestration; Imperial College Press, 2014.

(72) Lin, L.-C.; Berger, A. H.; Martin, R. L.; Kim, J.; Swisher, J. A.; Jariwala, K.; Rycroft, C. H.; Bhown, A. S.; Deem, M. W.; Haranczyk, M.; et al. In Silico Screening of Carbon-Capture Materials. Nat. Mater. 2012, 11, 633-641.

(73) Huck, J. M.; Lin, L.-C.; Berger, A. H.; Shahrak, M. N.; Martin, R. L.; Bhown, A. S.; Haranczyk, M.; Reuter, K.; Smit, B. Evaluating Different Classes of Porous Materials for Carbon Capture. Energy Environ. Sci. 2014, 7, 4132-4146.

(74) Joos, L.; Lejaeghere, K.; Huck, J. M.; Van Speybroeck, V.; Smit, B. Carbon Capture Turned Upside Down: High-Temperature
Adsorption \& Low-Temperature Desorption (HALD). Energy Environ. Sci. 2015, 8, 2480-2491. 